\title{
ИЗУЧЕНИЕ ЭЛЕМЕНТНОГО СОСТАВА ПЛОДОВ КАЛИНЫ ОБЫКНОВЕННОЙ И РЯБИНЫ ОБЫКНОВЕННОЙ РАЗЛИЧНЫМИ СОВРЕМЕННЫМИ МЕТОДАМИ
}

\author{
(C) В.Ю. Андреева*, Н.В. Исайкина, Т.Н. Цыбукова, Е.В. Петрова \\ Сибирский государственный медицинский университет, Московский тракт, \\ 2/7, Томск, 634050 (Россия), e-mail: vilival@yandex.ru
}

В официнальной медицине плоды калины обыкновенной (Viburnum opulus L., сем. Caprifoliaceae) применяются как потогонное и противовоспалительное средство, а рябины обыкновенной (Sorbus aucuparia L., сем. Rosaceae) - как поливитаминное средство. Кроме того, по экспериментальным исследованиям плоды калины обладают кардиотоническим, седативным, антиоксидантным, антигипоксическим и гипотензивным действием; а плоды рябины - иммунотропным действием. Данные виды фармакологической активности обусловлены комплексом биологически активных веществ: витаминами (C, P, B 2 Е, каротиноидами), фенольными соединениями (флавоноидами, фенолокислотами, антоцианами), гликозидами, полисахаридами, сахарами, органическими и тритерпеновыми кислотами, жирными маслами, макро- и микроэлементами. Особая роль принадлежит макро- и микроэлементам, содержащимся в исследуемых плодах в виде биодоступных комплексов. Поэтому целью нашего исследования было качественное обнаружение и количественное определение элементного состава плодов калины и рябины обыкновенной. Определение элементного состава проводили методами пламенной фотометрии, атомно-эмиссионной спектроскопии и нейтронно-активационного анализа. Изученные образцы содержат важные биогенные элементы, необходимые для лечения и профилактики заболеваний иммунной и сердечнососудистой систем, что позволяет использовать данное лекарственное растительное сырье как перспективное для получения на их основе эффективных лекарственных средств и пищевых добавок.

Ключевые слова: калина обыкновенная (Viburnum opulus L.), рябина обыкновенная (Sorbus aucuparia L.), элементный состав.

\section{Введение}

Калина обыкновенная (Viburnum opulus L.) и рябина обыкновенная (Sorbus aucuparia L.) - многолетние дикорастущие и культивируемые древесные растения, принадлежащие к семейству Жимолостные (Caprifoliaceae) и Розоцветные (Rosaceae) соответственно. Произрастают по всей Европейской России, на Урале, Кавказе, в Западной и Восточной Сибири $[1,2]$.

В официнальной медицине плоды калины обыкновенной применяются как потогонное и противовоспалительное средство, а рябины обыкновенной - как поливитаминное средство [3]. Кроме того, по экспериментальным исследованиям плоды калины обладают кардиотоническим, седативным, антиоксидантным, антигипоксическим и гипотензивным действием [1]; а плоды рябины - иммунотропным действием [4]. Данные виды фармакологической активности обусловлены комплексом биологически активных ве-

Андреева Валерия Юрьевна - кандидат биологических наук, доцент кафедры фармакогнозии с курсами ботаники и экологии; e-mail: vilival@yandex.ru Исайкина Надежда Валентиновна - кандидат фармацевтических наук, доцент кафедры фармакогнозии с курсами ботаники и экологии Цыбукова Татьяна Николаевна - кандидат химических наук, доцент кафедры общей химии

Петрова Елена Васильевна - кандидат химических наук, доцент кафедры аналитической химии ществ (БАВ): витаминами $\left(\mathrm{C}, \mathrm{P}, \mathrm{B}_{2}, \mathrm{E}\right.$, каротиноидами), фенольными соединениями (флавоноидами, фенолокислотами, антоцианами), гликозидами, полисахаридами, сахарами, органическими и тритерпеновыми кислотами, жирными маслами, макрои микроэлементами [5]. Среди перечисленных БАВ особая роль принадлежит макро- и микроэлементам, содержащимся в исследуемых плодах в виде био-

\footnotetext{
* Автор, с которым следует вести переписку.
} 
доступных комплексов. Элементы влияют на активность многих ферментов, входят в состав витаминов, гормонов и тем самым поддерживают гомеостаз организма. Нарушение оптимального баланса элементов в организме человека является причиной многих заболеваний [6].

Элементный состав плодов перечисленных видов, произрастающих в Европейской части России достаточно хорошо изучен [7-9]. Однако нами для получения лекарственных средств на основе плодов рябины и калины будут использоваться источники сырья, произрастающие в Сибири.

С учетом вышеизложенного возникла необходимость в качественном обнаружении и количественном определении элементного состава плодов калины и рябины обыкновенной, произрастающих и культивируемых в Сибирском регионе.

\section{Материальи и методы}

Для исследования использовали образцы плодов калины обыкновенной (Viburnum opulus L.) и рябины обыкновенной (Sorbus aucuparia L.), собранные в естественных местах произрастания растений и культивируемые в 2013 г. в различных областях Западной и Восточной Сибири в период созревания и высушенные до воздушно-сухого состояния.

Определение элементного состава проводили тремя современными физическими методами, дополняющими друг друга [10].

Для метода нейтронно-активационного анализа (НАА) характерна высокая чувствительность и сходимость результатов при анализе природных объектов, возможность определения большого числа элементов (до 30-35 из одной навески образца), малая величина требуемой навески [11]. Образцы анализировали на ядерном реакторе (пос. Спутник, Томск), снабженном анализаторной системой «CANBERRA» с детектором из чистого германия. 10,0 г (точная навеска) плодов озоляли. Полученную золу упаковывали в алюминиевую фольгу и вместе со стандартными образцами облучали на анализаторной системе фирмы «CANBERRA» с детектором из чистого германия типа GX - 3518 с размещением по Со60 (1332 кэв) 1,8 кэв. Облучение проводилось в вертикальном канале в потоке тепловых нейронов (плотность потока $\left.2,2 * 1013 \mathrm{H} / \mathrm{cm}^{2}\right)$ в течение 7 ч. Измерение проводили в 2 этапа: первый - время охлаждения - 7 дней, продолжительность измерения - 25 мин. Определяли: $\mathrm{Sm}, \mathrm{Ca}, \mathrm{Lu}, \mathrm{U}, \mathrm{Yb}, \mathrm{Au}, \mathrm{As}, \mathrm{Sb}, \mathrm{Br}, \mathrm{Na}, \mathrm{La}$ (короткоживущие изотопы). На втором этапе время охлаждения - 24 дня, продолжительность измерения - 60 мин. Определялись: Ce, Th, Cr, Hf, Ba, Sr, Ag, Cs, Sc, Rb, Fe, Zn, Ta, Co, Eu (долгоживущие изотопы).

Методом пламенной фотометрии выявляли содержание натрия и калия. Определение проводили на атомно-абсорбционном спектрометре SOLAAR M5 (THERMO ELECTRON, CШA) в режиме эмиссии с пламенным источником атомизации (пропан - бутан - воздух).

Атомно-эмиссионная спектроскопия (АЭС) с дуговым источником возбуждения и многоканальным анализатором эмиссионных спектров (МАЭС). В работе использовали атомно-эмиссионный комплекс «Гранд», включающий спектроаналитический генератор «Везувий-3», полихроматор «Роуланд» и многоканальный анализатор эмиссионных спектров МАЭС.

Данные получены усреднением 4-5 параллельных определений и обработаны методом математической статистики [12].

\section{Результаты и их обсуждение}

Методами пламенной фотометрии, АЭС и НАА в исследуемых образцах были выявлены 24 элемента, среди которых 3 макро- и 21 микроэлемент (табл.).

Как видно из таблицы, количественное содержание элементов в плодах, определенное перечисленными методами, сопоставимо. Различия в содержании некоторых элементов связаны с технологическими особенностями используемых методов.

Анализ данных литературы показал, что при коррекции патологии иммунитета и сердечнососудистой системы наибольшее значение имеют такие элементы как магний, цинк, железо, молибден, ванадий, кобальт. Так как в растениях эти элементы находятся в комплексах с другими биологически активными веществами, то их биодоступность повышается. Поэтому плоды рябины и калины могут быть дополнительными пищевыми источниками значимых элементов.

При этом содержание элементов с преобладающим токсическим действием на организм незначительно и не превышает предельно допустимых концентраций (Сан ПиН 2.3.2.560-02). 
Содержание элементов в плодах рябины обыкновенной и калины обыкновенной методами пламенной фотометрии, атомно-эмиссионной спектроскопии и методом нейтронно-активационного анализа (\%, а.с.с.)

\begin{tabular}{|c|c|c|c|c|c|}
\hline \multirow{2}{*}{$\begin{array}{c}\text { № } \\
\text { П/П }\end{array}$} & \multirow{2}{*}{ Элемент } & \multicolumn{2}{|c|}{ Плоды рябины обыкновенной } & \multicolumn{2}{|c|}{ Плоды калины обыкновенной } \\
\hline & & АЭС & HAA & АЭС & HAA \\
\hline 1 & K & $1,21^{*}$ & 1,17 & $0,82 *$ & 0,83 \\
\hline 2 & $\mathrm{Na}, \times 10^{-2}$ & $0,69^{*}$ & 0,22 & $0,57^{*}$ & 0,20 \\
\hline 3 & $\mathrm{Ca}, \times 10^{-2}$ & 8,67 & 13,40 & 3,66 & 4,10 \\
\hline 4 & $\mathrm{Mg}, \times 10^{-2}$ & 12,00 & - & 6,21 & - \\
\hline 5 & $\mathrm{~B}, \times 10^{-2}$ & 6,45 & - & 1,34 & - \\
\hline 6 & $\mathrm{Fe}, \times 10^{-2}$ & 0,46 & 0,32 & 0,21 & 0,35 \\
\hline 7 & $\mathrm{Zn}, \times 10^{-4}$ & 6,02 & 15,40 & 16,10 & 17,70 \\
\hline 8 & $\mathrm{Co}, \times 10^{-4}$ & 0,21 & 0,14 & 0,53 & 0,29 \\
\hline 9 & $\mathrm{Cu}, \times 10^{-4}$ & 2,73 & - & 2,25 & - \\
\hline 10 & $\mathrm{Mn}, \times 10^{-4}$ & 0,27 & - & 0,21 & - \\
\hline 11 & $\mathrm{Mo}, \times 10^{-4}$ & 0,88 & - & 0,45 & - \\
\hline 12 & $\mathrm{Li}, \times 10^{-4}$ & 0,17 & - & 0,79 & - \\
\hline 13 & $\mathrm{Sr}, \times 10^{-4}$ & 3,30 & 5,31 & 7,22 & 4,98 \\
\hline 14 & $\mathrm{Ba}, \times 10^{-4}$ & 2,90 & 8,46 & 1,42 & 5,74 \\
\hline 15 & $\mathrm{Cr}, \times 10^{-4}$ & 2,10 & 1,00 & 1,05 & 0,19 \\
\hline 16 & $\mathrm{Ag}, \times 10^{-6}$ & 6,03 & 8,06 & 12,10 & 11,90 \\
\hline 17 & $\mathrm{~Pb}, \times 10^{-6}$ & 79,2 & - & 93,00 & - \\
\hline 18 & $\mathrm{~V}, \times 10^{-6}$ & 44,7 & - & 37,70 & - \\
\hline 19 & $\mathrm{Rb}, \times 10^{-4}$ & - & 5,51 & - & 5,30 \\
\hline 20 & $\mathrm{Br}, \times 10^{-4}$ & - & 2,02 & - & 2,62 \\
\hline 21 & $\mathrm{Sb}, \times 10^{-6}$ & - & 1,65 & - & 0,93 \\
\hline 22 & $\mathrm{U}, \times 10^{-6}$ & - & 2,08 & - & 0,15 \\
\hline 23 & As, $\times 10^{-6}$ & - & 20,50 & - & 11,50 \\
\hline 24 & $\sum \mathrm{Ln}, \times 10^{-6}$ & - & 22,40 & - & 9,40 \\
\hline
\end{tabular}

Примечание: * - использован метод пламенной фотометрии.

\section{Выводы}

Изучение элементного состава плодов рябины и калины обыкновенной показало, что образцы содержат важные биогенные элементы, необходимые для лечения и профилактики заболеваний иммунной и сердечно-сосудистой систем. Полученные результаты позволяют использовать данное лекарственное растительное сырье как перспективное для дальнейшего изучения и получения на их основе эффективных лекарственных средств и пищевых добавок.

\section{Список литературь}

1. Растительные ресурсы России. Дикорастущие цветковые растения, их компонентный состав и биологическая активность. Т. 4: Семейства Caprifoliaceae - Lobeliaceae / под ред. Л. Беленовской, Е. Лесиовской. СПб.; М., 2009. $630 \mathrm{c}$.

2. Растительные ресурсы России. Дикорастущие цветковые растения, их компонентный состав и биологическая активность. Т. 2: Семейства Actinidiaceae - Malvaceae, Euphorbiaceae - Haloragaceae / под ред. А.Л. Буданцев. СПб.; М., 2009. 520 с.

3. Государственная Фармакопея СССР. М., 1989. 398 с.

4. Шукшина О.Г., Масная Н.В., Шерстобоев Е.Ю., Исайкина Н.В., Калинкина Г.И Влияние растительных полифенольных комплексов на функциональную активность иммунокомпетентных клеток in vitro // Иммунология, 2014. T. 35. №3. C. 138-142.

5. Лесиовская Е.Е. Доказательная фитотерапия. М., 2014. Т. 2. 686 с.

6. Скальный А.В. Химические элементы в физиологии и экологии человека. М., 2004. С. 216.

7. Сорокопудов В.Н., Алдошкин И.С., Колесников Д.А. Элементный состав плодов и семян некоторых видов и сортов калины в условиях юго-запада Среднерусской возвышенности // Научные ведомости Белгородского государственного университета. Серия: Естественные науки, 2012. Т. 21. №21-1 (140). С. 132-134.

8. Иванова С.В., Шелепова О.В., Кириченко Е.Б. Микроэлементный состав плодов рябины обыкновенной (Sorbus aucuparia L.) // Вестник Оренбургского государственного университета, 2005. №2 (40). С. 9-10

9. Чахирова А.А. Технологические исследования по разработке масляного экстракта из плодов рябины обыкновенной и перспективы его использования : автореф. ... канд. фарм. наук. Пятигорск, 2008. 24 с.

10. Гильберт Э.Н., Шабанова О.В. Современные многоэлементные методы анализа объектов окружающей среды // Сибирский химический журнал. 1992. Вып. 3. С. 5-14. 
11. Гурьев А.М., Юсубов М.С., Калинкина Г.И., Цыбукова Т.Н. Элементный состав аира болотного (Асоrus calamus L.) // Химия растительного сырья. 2003. №2. С. 45-48.

12. Доерфель К. Статистика в аналитической химии. М., 1969. С. 247.

Поступило в редакцию 5 ноября 2015 г. После переработки 6 января 2016 2.

\begin{abstract}
Andreeva V.Y.*, Isaykina N.V., Tsybukova T.N., Petrova E.V. THE STUDY OF THE ELEMENTAL COMPOSITION OF FRUITS OF VIBURNUM OPULUS L. AND SORBUS AUCUPARIA L. VARIOUS MODERN METHODS

\section{Siberian State Medical University, Moscovsky Trakt, 2/7, Tomsk634050 (Russia), e-mail: vilival@yandex.ru}

In medicine, the fruits of Viburnum opulus $L$. are used as a tonic, diaphoretic and diuretic, and Sorbus aucuparia L. - as a multivitamin means. Experimental studies have shown that viburnum fruits possess cardiotonic, sedative, antioxidant, antihypoxic and hypotensive action, and the fruits of mountain ash - immunotropic effect. These types of pharmacological activity depends on a complex of biologically active substances: vitamins (C, P, B2, E, carotenoids), phenolic compounds (flavonoids, phenolic acids, anthocyanins), glycosides, polysaccharides, sugars, and organic triterpene acids, fatty oils and macro - and microelements. A special role belongs to the macro - and micronutrients. Therefore, the aim of our study was qualitative detection and quantitative determination of element composition of fruits of Viburnum opulus and Sorbus aucuparia. Determination of elemental composition was performed by methods of flame photometry, atomic emission spectroscopy and neutron activation analysis. Studied samples contain important nutrients necessary for the treatment and prevention of diseases of the immune and cardiovascular systems. This allows the use of this material as promising for obtaining on their basis of effective medicines and nutritional supplements.
\end{abstract}

Keywords: Viburnum opulus, Sorbus aucuparia, elemental composition.

\title{
References
}

1. Rastitel'nye resursy Rossii. Dikorastushhie cvetkovye rastenija, ih komponentnyj sostav i biologicheskaja aktivnost'. T. 4: Semejstva Caprifoliaceae - Lobeliaceae [Plant Resources of Russia. Wild flowering plants, their composition and biological activity. Vol. 4: Family Caprifoliaceae - Lobeliaceae]. ed. L. Belenovskaja, E. Lesiovskaja. St. Petersburg, Moscow, 2009, 630 p. (in Russ.).

2. Rastitel'nye resursy Rossii. Dikorastushhie cvetkovye rastenija, ih komponentnyj sostav i biologicheskaja aktivnost'. T. 2: Semejstva Actinidiaceae - Malvaceae, Euphorbiaceae - Haloragaceae [Plant Resources of Russia. Wild flowering plants, their composition and biological activity. Vol. 2: Families Actinidiaceae - Malvaceae, Euphorbiaceae Haloragaceae]. ed. A.L. Budancev. St. Petersburg, Moscow, 2009, 520 p. (in Russ.).

3. Gosudarstvennaja Farmakopeja SSSR. [State Pharmacopoeia of the USSR]. Moscow, 1989, 398 p. (in Russ.).

4. Shukshina O.G., Masnaja N.V., Sherstoboev E.Ju., Isajkina N.V., Kalinkina G.I. Immunologija, 2014, vol. 35, no. 3, pp. 138-142. (in Russ.).

5. Lesiovskaja E.E. Dokazatel'naja fitoterapija. [Evidence phytotherapy]. Moscow, 2014, vol. 2, 686 p. (in Russ.).

6. Skal'nyj A.V. Himicheskie jelementy v fiziologii i jekologii cheloveka. [Chemical elements in the human physiology and ecology]. Moscow, 2004, p. 216. (in Russ.).

7. Sorokopudov V.N., Aldoshkin I.S., Kolesnikov D.A. Nauchnye vedomosti Belgorodskogo gosudarstvennogo universiteta. Serija: Estestvennye nauki, 2012, vol. 21, no. 21-1 (140), pp. 132-134. (in Russ.).

8. Ivanova S.V., Shelepova O.V., Kirichenko E.B. Vestnik Orenburgskogo gosudarstvennogo universiteta, 2005, no. 2 (40). pp. 9-10. (in Russ.).

9. Chahirova A.A. Tehnologicheskie issledovanija po razrabotke masljanogo jekstrakta iz plodov rjabiny obyknovennoj i perspektivy ego ispol'zovanija: avtoref. Diss ... kand. farm. nauk. [Technological research on the development of an oil extract from the fruit of mountain ash, and the prospects for its use: Abstract. diss ... The candidate of pharmaceutical sciences]. Pjatigorsk, 2008, 24 p. (in Russ.).

10. Gil'bert Je.N., Shabanova O.V. Sibirskij himicheskij zhurnal, 1992, no. 3, pp. 5-14. (in Russ.).

11. Gur'ev A.M., Jusubov M.S., Kalinkina G.I., Cybukova T.N. Himija rastitel'nogo syr'ja, 2003, no. 2, pp. 45-48. (in Russ.).

12. Doerfel' K. Statistika v analiticheskoj himii. [Statistics in analytical chemistry]. Moscow, 1969, p. 247. (in Russ.).

\footnotetext{
* Corresponding author.
} 